\title{
Effectiveness of a result-based motivational system to reduce the behavioral risk factors of Non-Communicable Diseases: A Field Trial Study
}

\author{
Mehran Asadi-Aliabadi \\ Iran University of Medical Sciences https://orcid.org/0000-0003-1582-5489 \\ Seyed M Karimi \\ University of Louisville School of Public Health and Information Sciences \\ Fariba Mirbaha-Hashemi \\ Iran University of Medical Sciences \\ Arash Tehrani-Banihashemi \\ Iran University of Medical Sciences \\ Leila Janani \\ Iran University of Medical Sciences \\ Ebrahim Babaee \\ Iran University of Medical Sciences \\ Marzieh Nojomi \\ Iran University of Medical Sciences \\ Maziar Moradi-Lakeh ( $\nabla$ moradilakeh.m@iums.ac.ir) \\ Iran University of Medical Sciences https://orcid.org/0000-0001-7381-5305
}

\section{Research Article}

Keywords: NCDs Risk Factors, Randomized Field Trial, Non-Physician Health Worker, Evidence-Based Training, Performance-Based Financing.

Posted Date: February 22nd, 2022

DOI: https://doi.org/10.21203/rs.3.rs-1286619/v1

License: (c) (i) This work is licensed under a Creative Commons Attribution 4.0 International License. Read Full License 


\section{Abstract}

Background: Noncommunicable diseases behavioral risk factors are the most important modifiable risk factors. They can be improved as long as the relevant interventions are designed in accordance with the context of the health system and its resources in different regions. In this trial, the effectiveness of intervention packages focusing on increasing non-physician health workers' motivation to reduce non-communicable diseases behavioral risk factors was evaluated.

Methods: A randomized field trial study was conducted in 32 community health centers in 4 Iranian districts after a baseline population survey on 30-70-year-old individuals ( $n=1225)$. The interventions were performed to improve insufficient physical activity, fruit consumption, vegetable consumption, high salt intake, and tobacco use. Four packages of interventions were implemented in 24 community health centers; the other 8 centers were used as control groups. The non-physician health workers performed the interventions. The packages included different mixtures of 4 components: goal-setting, evidence-based education, operational planning, and incentive payments. A second survey was conducted one year after the start of the interventions to identify the effects on an independent random sample $(n=1221)$. The difference-in-difference method was used to quantify the interventions' effects.

Results: The average age of participants in both surveys was about 49 years. Also, in both surveys, about half of the participants were female, and about $43 \%$ were either illiterate or had primary school education. The interventions had statistically significant effects only on decreasing the prevalence of insufficient physical activity. The package with all the intervention components decreased the odds of insufficient physical activity to $0.24(95 \% \mathrm{Cl}: 0.08,0.72)$. The packages with operational planning but no performance-based financing did not change the odds of insufficient physical activity.

Conclusions: This study highlighted the importance of components, design, and implementation details of interventions intended to reduce NCDs behavioral risk factors. Some risk factors such as physical activity seem to be more easily modifiable with limited low-cost interventions in a one-year horizon. However, risk factors related to the consumption of healthy food and tobacco use need larger, macro-level interventions.

Trial Registration: This trial registered on the Iranian Registry of Clinical Trials (IRCT20081205001488N2) on 3 June 2018 (https://en.irct.ir/trial/774 ).

\section{Background}

Noncommunicable diseases (NCDs) are the leading cause of death worldwide, as they accounted for $74 \%$ of total deaths and $85 \%$ of premature deaths in low- and middle-income countries (LMICs) in 2019 [1, 2]. In 2015, the United Nations (UN) acknowledged that the increase in the burden of NCDs is a major threat to its Sustainable Development Goals (SDGs) for the 21st century and targeted to reduce NDCs' premature deaths to one-third by 2030 [3] In Iran, NCDs mortality increased from 49-82\% from 1990 to 2017 [4]. In 2017, the loss of 7.0 million years of life was attributed to NDCs, indicating a $98 \%$ increase from 1990. Also, 15.0 million years were lived with disability due to NDCs, showing a $48 \%$ increase from 1990 [5, 6].

Structural social changes such as rapid urbanization, globalization, and population aging have accelerated the prevalence of NCDs [7]. Changes in social structures are followed by lifestyle changes and increased prevalence of behavioral risk factors such as unhealthy diet, physical inactivity, tobacco smoking, and alcohol use [8]. Behavioral risk factors precede the development of metabolic risk factors (e.g., raised blood pressure, overweight/obesity, and increased blood cholesterol) then progress to NCDs in populations [9]. According to the World Health Organization (WHO), 1.6 million preventable deaths per year are caused by physical inactivity, 7.2 by tobacco use, 4.1 by excess salt/sodium intake, and 3.9 by inadequate fruits and vegetable consumption $[10,11]$. These estimates indicate the importance of behavioral risk factors as preventable contributors to the development of NCDs [10].

According to a 2019 report, $16.5 \%$ of the country's deaths were attributed to an unhealthy diet, $14.1 \%$ to tobacco use, $4.4 \%$ to inadequate physical activity, and $1.2 \%$ to excess salt intake. The corresponding attributable DALYs to the risk factors were $7.5 \%, 9.2 \%, 1.9 \%$, and $0.6 \%$, respectively [1]. Therefore, effective investments in curtailing NCDs risk factors can save and improve lives, and hence will be economically justifiable if at-risk people are identified in the early stages [12].

Many cost-effective intervention methods to control NCDs have been introduced worldwide14. However, the main challenge is implementing them in LMICs, which typically face a limited skilled workforce, financial resources, and community participation [13]. Efforts to control the increasing rate of NCDs in Iran started in 2014 by launching an adaptation of the WHO's Package of Essential, IraPEN [14]. However, the mismatch of typical training provided to health care workers with the extent of NCDs in the community, insufficient documentation to determine the existing NCDs' status, inconsistency between training and practice, and instability of financial resources have obstructed the successful implementation of the package [15, 16].

In this study, a field trial was devised and carried out to address the above shortcomings. A set of Intervention Packages were designed to encourage reducing NCD behavioral risk factors and implemented by non-physician community health workers (NPHWs) in a group of randomly selected community health centers (CHCs) in four Iranian districts. The NPHWs were informed about the status of NCD behavioral risk factors in the catchment areas and a set of goals to reduce the risk factors. Then, they randomly received none or at least one of the following interventions: evidence-based training, receiving an action plan to reduce the risk factors based on the NCDs status of their corresponding CHCs, and receiving incentive payments 
based on their performance in achieving the goals. The trial was conducted to understand the effects of these interventions on NCD risk factors in the studied population.

\section{Methods Study sample}

This study was part of a larger project with a published protocol [17].In a nutshell, four districts (or counties) were selected for field trial. One of the districts (Garmsar) was considered the no-intervention, and the other three were intervention districts. In each selected district, four urban and four rural $\mathrm{CHCs}$ were selected. In each of the 32 selected CHCs, a baseline survey was conducted on 30 - 70-year-old residents to understand the existing status of NCDs risk factors from June to September 2018 using a Farsi translation of adapted WHO stepwise approach to surveillance (STEPS) questionnaires [18]. Then, four different Intervention Packages were randomly assigned to selected urban or rural $\mathrm{CHC}$ in the intervention districts. In effect, one urban and one rural $\mathrm{CHCs}$ in any of the intervention districts received the Intervention Packages $\mathrm{A}$, one urban and one rural $\mathrm{CHCs}$ in the district received the Intervention Package $B$, and so on. The interventions period was 12 months, after which the second survey was conducted on the same age population in the $32 \mathrm{CHCs}$ to assess the impacts of the interventions from September to November 2019 (Fig. 1). We used a random sample of the general population. The sampling method was similar in both surveys, but the selected participants were not necessarily the same. The NPHWs in each $\mathrm{CHCs}$ were responsible for planning and running the interventions in their catchment area, with or without extra help by the core team of research (by education, consultation on operation planning or paying for performance). Although the survey participants were expected to be among the target groups of the interventions, they were not necessarily the ones who received the intervention directly. This is similar to the real situation where interventions do not necessarily affect all the target population.

Based on the approved protocol, the trial was planned to continue for 24 months, with a third survey at the end of the study. However, to comply with the country's COVID-19 social distancing protocols, the trial was terminated prematurely after 12 months of interventions.

The selected districts were Shahriar (population = 744,210), Dashtestan (population = 252,047), Damghan (population = 94,190), and Garmsar (population $=77,421$ ) (Additional file 1). The districts' populations are based on the 2016 census [19]. A simple randomization method was used to select four urban and four rural CHCs in each district and to assign the Intervention Packages to the selected CHCs. Detailed explanations on the inclusion criteria for the districts, CHCs, and participants were explained in the protocol [17]. NPHWs implemented the four interventions packages after receiving extensive training. Physicians were not the target group of this trial because they were undergoing a separate incentive payment scheme [20]. The CONSORT checklist can be found in Additional file 2[21].

\section{Interventions}

An Intervention Package included at least one of the following interventions.

First intervention (target-setting): Short-term targets (e.g., decrease in tobacco use and salt consumption) were set based on the preliminary results obtained from the baseline survey. NPHWs were entirely responsible for planning to achieve the targets. In the first intervention, meetings were held with the NPHWs and they were informed about the status of NCD behavioral risk factors in their catchment area population (based on the first survey) and the national goals (it is set until 2025) to control NCDs behavioral risk factors were explained to them (Reduce tobacco use by $30 \%$, Reduce insufficient physical activity by $20 \%$, Reduce average salt intake by $30 \%$, Reduce the consumption of fruits and vegetables in insufficient servings by $30 \%)$.

Second intervention (evidence-based education): The main research team reviewed and prepared documents on the effect of the interventions on the prevention of NCDs risk factors. After approval, these documents were shared with NPHWs and health experts during 16-hour workshops. we trained NPHWs about the methods of selecting, planning and implementing cost-effective and feasible interventions in catchment areas of community health center using Disease Control Priorities volumes 3 [22, 23], and the WHO package of essential NCDs (PEN) [24].

Third intervention (operational planning): The research team coordinated with NPHWs and health experts to devise operational plans based on the priorities of each $\mathrm{CHC}$ during a 12-hour workshop at each district. Also, the team allocated a supportive budget for the devised operational plans.

Fourth intervention (performance-based financing or PBF): The pay-for-performance method of financing was implemented. The incentives were paid in accordance with the pre-defined targets and indices every three months. The indicators of performance were set based on the objectives of the national document for the prevention and control of NCDs and related risk factors in Iran [25]. The maximum amount of incentive payment was paid to NPHWs who met $62.50 \%$ (5 out of 8 ) to $100 \%$ (8 out of 8 ) of their targeted goals. The maximum monthly incentive amount was $10 \%$ of the average monthly salary to NPHWs in the studied districts, which was determined to be approximately 25 million Rial (or 232 USD at a 107,832 Rial/USD current exchange rate [26]) after interviewing the district's provincial supervisors appointed by the Iranian MOHME. Therefore, the full monthly incentive payment was approximately 23 USD. NPHWs who did not meet their goals were paid proportionally less. Specifically, those who met $50.00 \%$ (4 out of 8) to $62.49 \%$ (4 out of 8 plus partially meeting other ones) of their goals received two-third of the full amount, approximately 15 USD monthly in the corresponding three-month assessment period. Those who met $25.00 \%$ ( 2 out of 8 ) to $49.99 \%$ ( 2 out of 8 plus partially meeting other ones) of their goals received one-third of the full amount, approximately 8 USD monthly. Those achieving less than $25 \%$ of their goal received no incentive payment. No payment was delayed because they were made directly to the NPHWs' bank account by the research team immediately after each assessment. 
Specifically, Intervention Package A included only the first intervention. Intervention Package B included the first two interventions. Intervention Package $C$ included the first three interventions. Intervention Package $D$ included all four interventions (Table 1). CHCs that received Intervention Packages $A, B, C$, and D are also called intervention groups $A, B, C$, and D in this study respectively. The no-intervention control group (Garmsar district) received none of the interventions.

Every two to four weeks, the implementation status of the interventions was reviewed and checked by the district and province supervisors selected by the research team. Also, reports and documents related to interventions were received by the research team every quarter.

Table 1

Assignment of interventions to $\mathrm{CHCs}$ inside each of the three treatment districts

\begin{tabular}{|c|c|c|c|c|c|}
\hline \multirow{2}{*}{$\begin{array}{l}\text { Intervention } \\
\text { Package }\end{array}$} & \multirow{2}{*}{$\begin{array}{l}\text { Intervention Groups: Selected } \\
\text { CHCs }\end{array}$} & \multicolumn{4}{|c|}{ Intervention: } \\
\hline & & $\begin{array}{l}\text { Target- } \\
\text { Setting }\end{array}$ & $\begin{array}{l}\text { Evidence-Based } \\
\text { Education }\end{array}$ & $\begin{array}{l}\text { Operational } \\
\text { Planning }\end{array}$ & $\begin{array}{l}\text { Performance-Based } \\
\text { Financing }\end{array}$ \\
\hline$A$ & 1 Rural, 1 Urban & Yes & No & No & No \\
\hline B & 1 Rural, 1 Urban & Yes & Yes & No & No \\
\hline C & 1 Rural, 1 Urban & Yes & Yes & Yes & No \\
\hline $\mathrm{D}$ & 1 Rural, 1 Urban & Yes & Yes & Yes & Yes \\
\hline
\end{tabular}

\section{Statistical analysis}

This study's objective was to compare NCDs Behavioral risk factors before and after the interventions and identifying effective interventions. NCDs Behavioral risk factors analyzed in this study were zero-one indicators of insufficient physical activity, insufficient fruit consumption, insufficient vegetable consumption, high salt intake, and tobacco use.

Not meeting the WHO recommendations on physical activity Metabolic Equivalent of Task (MET) (less than 600 METs per week) was defined as insufficient physical activity [27]. The WHO's recommendations were used to determine insufficient fruits (less than two medium fruits, such as two medium apples or half a cup of nuts, in the last 24 hours) and vegetable consumption (less than three cups of raw leafy vegetables or one and a half cups of cooked or chopped vegetables in the last 24 hours) as well [28-30]. A person was identified as high salt consumer if the person always or often added salt or salt additives to the food [31]. Current tobacco smoking was defined as the use of any smoked tobacco products, including cigarettes, cigars, pipes, or any other smoked tobacco products, on a daily, non-daily basis in the last 30 days [32].

The prevalence of each NCDs risk factor in the baseline and second surveys was calculated in populations assigned with each Intervention Package. Then, the difference in the prevalence rates between the two surveys was calculated. For the more formal analysis of the effect of the designed Intervention Packages, the difference-in-difference (DID) design was employed. The following equation shows the linear specification of the DID design:

Equation 1.

$$
\mathrm{Y}_{\mathrm{ict}}=\alpha+\beta \text { IntPackage }_{\mathrm{ic}}+\gamma \text { Post }_{\mathrm{it}}+\rho\left(\text { IntPackage }_{\mathrm{ic}} \times \text { Post }_{\mathrm{it}}\right)+\theta \mathrm{CHC}_{\mathrm{it}}+\delta \mathrm{X}_{\mathrm{ict}}+\epsilon_{\mathrm{ict}}
$$

where $\mathrm{i}$ indicates a surveyed individual, $\mathrm{c}$ indicated the community health center to which the individual is affiliated, and $\mathrm{t}$ indicates survey year. The dependent variable, $\mathrm{Y}$, is a binary variable that indicates one of the NCDs risk factors for the individual. The variable IntPackage is a categorical variable with five values $(0,1,2,3$, and 4$)$ that indicates which Intervention Package (listed in Table 1$)$ was assigned to the $\mathrm{CHC}$ that the individual receives health services from. The value zero was assigned to those in control (no intervention) group. The variable Post indicates the survey year. It takes the value of 0 if the individual was surveyed before the implementation of the interventions in 2018,1 if surveyed after in 2019 . The variable $\mathrm{CHC}$ is a health center indicator $(1,2, \ldots, 32)$ as people subjected to a specific Intervention Package could be affiliated to different health centers. This variable accounts for the influence of all unobservable/unmeasurable $\mathrm{CHC}$-specific confounders that might not change over the one-year period of this study (e.g., health care resources in the community, attitudes towards using modern medicine versus traditional practices, distance from the CHCs, and overall weather patterns). The variable $\mathrm{X}$ is a vector of socioeconomic factors including age, sex, marital status (in three categories: never married, married, divorced or widowed), education level (in four categories: illiterate or primary, secondary, high school, and some college), labor market status (in six categories: public wage and salary job, private wage and salary job, self-employed, homemaker, retired, and unemployed), health insurance status, and homeownership status. The coefficient of interest in this specification is $\rho$ that shows the effect of Intervention Package i (versus no intervention, for example) among those surveyed after the intervention.

Given the binary nature of the outcome variables in this study, logistic models were used in fitting Eq. 1. Odds ratios were calculated, representing the change in the odds of the dependent variable being equal to 1 due to one unit change in either of the terms on the right-hand side of Eq. 1 , a transforming the logistic model results in:

Equation 2. 


$$
\ln \left(\frac{\mathrm{p}_{\mathrm{Y}_{\text {ict }}}}{1-\mathrm{p}_{\mathrm{Y}_{\mathrm{ict}}}}\right)=\alpha+\beta \text { IntPackage }_{\mathrm{ic}}+\gamma \text { Post }_{\mathrm{it}}+\rho\left(\text { IntPackage }_{\mathrm{ic}} \times \text { Post }_{\mathrm{it}}\right)+\theta \mathrm{CHC}_{\mathrm{it}}++\delta \mathrm{X}_{\mathrm{ict}}+\mathrm{\epsilon}_{\mathrm{ict}}
$$

where $p_{-}\left(Y \_i c t\right)$ is the probability of $Y_{-} i c t=1$. To account for the possibility that the NCDs risk factors (the Ys) may not be independently distributed within the population covered by each community health center, hence the estimated standard error be artificially low, standard errors were clustered at the $\mathrm{CHC}$ level [33].

The Sampling weight assigned to a surveyed individual was the multiplication of two ratios. One was the individual's corresponding district's share of the same age group and sex in the country's population. The considered age groups were $30-39,40-49,50-59,60-70$, and the shares for urban and rural areas were calculated separately. The second was the share of surveyed people of the same age group and sex in the individual's corresponding $\mathrm{CHC}$.

To assess the extent of any potential bias in the selection of CHCs and the assignment of Intervention Packages, the estimations were done with and without adjusting for a set of measured socioeconomic factors, represented by X. The statistical package used for analyses was STATA 14.0 (Stata, Inc, College Station, Texas).

\section{Ethical Issues/statement}

This study has been approved by the national committee on ethics in medical research (code: IR.NIMAD.REC.1396.084) as well as our institutional review board (code: IR.IUMS.REC.1395.1057613). Written informed consent will be obtained from study participants.

\section{Results}

A total of 2446 people aged 30-70 years participated in the two surveys, 1225 individuals in the first survey and 1221 in the second survey. The mean age of the participants in the first survey was $49.3,49.4$ years in the second survey. The male participants accounted for $49.9 \%$ and $49.6 \%$ of the first and second surveys, respectively. A large proportion of the first and second surveys' participants were either illiterate or had primary school education ( $43.5 \%$ and $42.5 \%$, respectively). On the other hand, only $11 \%$ of the two surveys participant had some college education. The majority of the participants were married, with an $85.4 \%$ share in both surveys. In terms of job type, the majority belonged to homemakers (42.3\% and $46.5 \%$ in the first and second survey), then the self-employed (27.2\% and $24.1 \%$ ) and public and private wage and salary workers (17.7\% and $13.8 \%)$. In addition, most participants had health insurance ( $92.3 \%$ and $94.7 \%$ ). Finally, homeownership among the participants was $83.8 \%$ and $85.1 \%$ in the first and second surveys, respectively (Table 2 ).

There was no significant difference in the average age and sex of participants who received different Intervention Packages. The share of participants with primary or no education in the non-intervention group ( $25.8 \%$ and $23.7 \%$ in the first and second survey) was much lower than that in the intervention groups (between $36.5 \%$ and $55.5 \%$ ). Consequently, there were more participants with high school and college education in the nonintervention groups than the intervention groups. In addition, the difference in the share of high school educated people between the two surveys in intervention group A and that in the share of illiterate or primary school educated people in intervention group D was more than $10 \%$. Most surveyed individuals were married, regardless of the Intervention Packages assigned to their pertinent CHCs (between $81.9 \%$ and $90.4 \%$ across intervention groups and surveys). Also, the majority of participants were either homemakers (between $34.4 \%$ and $49.8 \%$ ) or self-employed (between $14.5 \%$ and 40.6\%), had health insurance (between 78.8\% and 98.4\%), and were homeowners (between 70.7\% and 92.9\%) (Table 2). Given the observed variations in the characteristics, statistical analyses were conducted after adjusting for them.

The crude comparison of the levels of NCDs risk factors in each intervention group before and after the interventions showed the largest decrease in insufficient physical activity in the intervention group D with a $29 \%$ decrease (95\% Confidence Interval: $20 \%, 38 \%$ ) then in groups B and A with $25 \%$ (95\% Cl: $17 \%, 34 \%)$ and 15\% (95\% Cl: 6\%, 24\%) decreases, respectively. The observed level of physical activity did not change in the control group during the study period. A consistent increase in fruit consumption was also observed in all intervention groups, but it also increased in the nonintervention group. No consistent and statistically significant pattern of increase or decrease in fruit and vegetable consumption, high salt intake, and tobacco use was observed in the studied groups (Table 3).

The results of the statistical analyses largely confirmed the results of the crude comparisons. Using the non-intervention district as the reference group and employing a DID research design (Eq. 2), no improvement in fruit and vegetable consumption, high salt intake, and tobacco use was estimated. However, consistent improvements in the level of physical activity in all intervention groups were observed compared to the non-intervention group. Among the Intervention Packages, B and D resulted in statistically significant improvements increasing the level of insufficient physical activity.

Specifically, the unadjusted estimations showed that the odds of reporting insufficient physical activity decreased to 0.32 (95\% $\mathrm{Cl}$ : $0.11,0.88)$ among the surveyed individuals covered by $\mathrm{CHCs}$ that received the Intervention Package $\mathrm{B}$, to $0.28(95 \% \mathrm{Cl}: 0.10,0.75)$ among those covered by $\mathrm{CHC}$ that received the Intervention Package D.These results were confirmed after adjusting for socioeconomic factors: $0.27(95 \% \mathrm{Cl}$ : $0.09,0.85)$ decrease in the odds of insufficient physical activity in intervention group B, $0.24(95 \% \mathrm{Cl}: 0.08,0.72)$ in intervention group D (Table 4). In other words, the package with 
all intervention components (with added the provision of an action plan and incentive payments to NPHWs to the previous two) decreased the likelihood of insufficient physical activity by $76 \%$ ( $95 \% \mathrm{Cl}: 28 \%, 92 \%)$. 
Table 2

Demographic and economic characteristics of participants in each group in the two surveys

\begin{tabular}{|c|c|c|c|c|c|c|c|c|c|c|c|c|}
\hline \multirow{5}{*}{$\begin{array}{l}\text { Socioeconomic } \\
\text { Factors }\end{array}$} & \multirow{2}{*}{\multicolumn{2}{|c|}{$\begin{array}{l}\text { Total } \\
\mathbf{n}=\mathbf{2 4 4 6}\end{array}$}} & \multicolumn{10}{|c|}{ Intervention Package/Group } \\
\hline & & & \multicolumn{2}{|l|}{$\begin{array}{l}A \\
n=445\end{array}$} & \multicolumn{2}{|l|}{$\begin{array}{l}B \\
n=463\end{array}$} & \multicolumn{2}{|l|}{$\begin{array}{l}C \\
n=465\end{array}$} & \multicolumn{2}{|l|}{$\begin{array}{l}D \\
n=450\end{array}$} & \multicolumn{2}{|l|}{$\begin{array}{l}\text { None } \\
n=623\end{array}$} \\
\hline & $\begin{array}{l}\text { Survey } \\
1\end{array}$ & $\begin{array}{l}\text { Survey } \\
2\end{array}$ & \multirow{3}{*}{$\begin{array}{l}\text { Survey } \\
1 \\
n= \\
225\end{array}$} & $\begin{array}{l}\text { Survey } \\
2\end{array}$ & $\begin{array}{l}\text { Survey } \\
1\end{array}$ & $\begin{array}{l}\text { Survey } \\
2\end{array}$ & $\begin{array}{l}\text { Survey } \\
1\end{array}$ & $\begin{array}{l}\text { Survey } \\
2\end{array}$ & $\begin{array}{l}\text { Survey } \\
1\end{array}$ & $\begin{array}{l}\text { Survey } \\
2\end{array}$ & \multirow{3}{*}{$\begin{array}{l}\text { Survey1 } \\
n= \\
305\end{array}$} & $\begin{array}{l}\text { Survey } \\
2\end{array}$ \\
\hline & $\mathrm{n}=$ & $\mathrm{n}=$ & & \multirow[t]{2}{*}{$\begin{array}{l}n= \\
220\end{array}$} & \multirow[t]{2}{*}{$\begin{array}{l}n= \\
232\end{array}$} & \multirow[t]{2}{*}{$\begin{array}{l}n= \\
231\end{array}$} & \multirow[t]{2}{*}{$\begin{array}{l}n= \\
239\end{array}$} & \multirow[t]{2}{*}{$\begin{array}{l}n= \\
226\end{array}$} & $\begin{array}{l}n= \\
224\end{array}$ & $\begin{array}{l}n= \\
226\end{array}$ & & \\
\hline & 1225 & 1221 & & & & & & & & & & 318 \\
\hline Mean Age & 49.3 & 49.4 & 49.5 & 49.6 & 49.3 & 49.3 & 49.9 & 49.1 & 48.9 & 49.1 & 48.8 & 49.7 \\
\hline $\begin{array}{l}\text { (Standard } \\
\text { Deviation) }\end{array}$ & $(0.33)$ & $(0.32)$ & & $(0.74)$ & $(0.73)$ & $(0.76)$ & $(0.73)$ & $(0.74)$ & $(0.78)$ & $(0.73)$ & $(0.65)$ & $(0.63)$ \\
\hline Sex: & & & & & & & & & & & & \\
\hline Male & 611 & 606 & 112 & 107 & 117 & 117 & 113 & 107 & 110 & 117 & 159 & 158 \\
\hline (\%) & $(49.9)$ & $(49.6)$ & $(49.8)$ & $(48.6)$ & $(50.4)$ & $(50.6)$ & $(47.3)$ & $(47.4)$ & $(49.1)$ & $(51.8)$ & $(52.1)$ & $(49.7)$ \\
\hline Female & 614 & 615 & 113 & 113 & 115 & 114 & 126 & 119 & 114 & 109 & 146 & 160 \\
\hline$(\%)$ & $(50.1)$ & $(50.4)$ & $(50.2)$ & $(51.4)$ & $(49.6)$ & $(49.4)$ & $(52.7)$ & $(52.6)$ & $(50.9)$ & $(48.2)$ & $(47.9)$ & $(50.3)$ \\
\hline Education: & & & & & & & & & & & & \\
\hline Illiterate or Primary & 497 & 517 & 105 & 122 & 109 & 116 & 117 & 121 & 88 & 83 & 78 & 75 \\
\hline$(\%)$ & $(43.5)$ & $(42.5)$ & $(50.0)$ & $(55.5)$ & $(49.1)$ & $(50.4)$ & $(52.5)$ & $(53.8)$ & $(47.3)$ & $(36.7)$ & $(25.8)$ & $(23.7)$ \\
\hline Secondary School & 158 & 196 & 19 & 35 & 39 & 39 & 20 & 30 & 27 & 44 & 53 & 48 \\
\hline (\%) & $(13.8)$ & $(16.1)$ & $(9.0)$ & $(15.9)$ & $(17.6)$ & $(17.0)$ & $(9.0)$ & $(13.3)$ & $(14.5)$ & $(19.5)$ & $(17.6)$ & $(15.1)$ \\
\hline High School & 365 & 368 & 65 & 43 & 58 & 64 & 68 & 52 & 45 & 70 & 129 & 139 \\
\hline$(\%)$ & $(31.9)$ & $(30.2)$ & $(31.0)$ & $(19.6)$ & $(26.1)$ & $(27.8)$ & $(30.5)$ & $(23.1)$ & $(24.2)$ & (31) & $(42.7)$ & $(43.9)$ \\
\hline Some College & 123 & 137 & 21 & 2 & 16 & 11 & 18 & 22 & 26 & 29 & 42 & 55 \\
\hline (\%) & $(10.8)$ & $(11.2)$ & $(10.0)$ & $(9.0)$ & $(7.2)$ & $(4.8)$ & $(8.0)$ & $(9.8)$ & $(14.0)$ & $(12.8)$ & $(13.9)$ & $(17.3)$ \\
\hline Marital Status: & & & & & & & & & & & & \\
\hline Never Married & 82 & 84 & 12 & 7 & 9 & 13 & 18 & 12 & 19 & 22 & 24 & 30 \\
\hline (\%) & $(7.0)$ & $(6.9)$ & $(5.7)$ & $(3.2)$ & $(4.0)$ & $(5.7)$ & $(8.1)$ & $(5.4)$ & $(9.0)$ & $(9.7)$ & $(7.9)$ & $(9.4)$ \\
\hline Married & 996 & 1039 & 187 & 198 & 190 & 194 & 187 & 198 & 176 & 185 & 256 & 264 \\
\hline (\%) & $(85.4)$ & $(85.4)$ & $(89.5)$ & $(90.4)$ & $(86.0)$ & $(84.7)$ & $(84.2)$ & $(88.4)$ & $(83.0)$ & $(81.9)$ & $(84.8)$ & $(83.0)$ \\
\hline Divorced/Widowed & 88 & 93 & 10 & 14 & 22 & 22 & 17 & 14 & 17 & 19 & 22 & 24 \\
\hline$(\%)$ & $(7.6)$ & $(7.7)$ & $(4.8)$ & $(6.4)$ & $(10.0)$ & $(9.6)$ & $(7.7)$ & $(6.2)$ & $(8.0)$ & $(8.4)$ & $(7.3)$ & $(7.6)$ \\
\hline Job: & & & & & & & & & & & & \\
\hline Public Wage and & 101 & 75 & 13 & 8 & 18 & 14 & 16 & 15 & 20 & 13 & 34 & 25 \\
\hline (\%) & $(8.7)$ & $(6.2)$ & $(6.3)$ & (3.6) & $(8.1)$ & $(6.1)$ & $(7.2)$ & $(6.8)$ & $(9.4)$ & $(5.8)$ & $(11.4)$ & $(7.9)$ \\
\hline Private Wage and & 104 & 92 & 21 & 31 & 21 & 15 & 28 & 21 & 12 & 18 & 22 & 7 \\
\hline (\%) & $(9.0)$ & $(7.6)$ & $(10.1)$ & $(14.0)$ & $(9.5)$ & $(6.5)$ & $(12.7)$ & $(9.6)$ & $(5.7)$ & $(8.1)$ & $(7.4)$ & $(2.2)$ \\
\hline Self-Employed & 316 & 292 & 53 & 46 & 54 & 56 & 32 & 49 & 86 & 58 & 91 & 83 \\
\hline$(\%)$ & $(27.2)$ & $(24.1)$ & $(25.5)$ & $(20.8)$ & $(24.3)$ & $(24.6)$ & $(14.5)$ & $(22.3)$ & $(40.6)$ & $(26.0)$ & $(30.5)$ & $(26.1)$ \\
\hline Homemaker & 491 & 563 & 89 & 103 & 98 & 110 & 110 & 105 & 73 & 102 & 121 & 143 \\
\hline (\%) & $(42.3)$ & $(46.5)$ & $(42.8)$ & $(47.1)$ & $(44.1)$ & $(47.8)$ & $(49.8)$ & $(47.7)$ & $(34.4)$ & $(45.7)$ & $(40.6)$ & $(45.0)$ \\
\hline
\end{tabular}




\begin{tabular}{|c|c|c|c|c|c|c|c|c|c|c|c|c|}
\hline \multirow{5}{*}{$\begin{array}{l}\text { Socioeconomic } \\
\text { Factors }\end{array}$} & \multirow{2}{*}{\multicolumn{2}{|c|}{$\begin{array}{l}\text { Total } \\
n=2446\end{array}$}} & \multicolumn{10}{|c|}{ Intervention Package/Group } \\
\hline & & & \multicolumn{2}{|l|}{$\begin{array}{l}A \\
n=445\end{array}$} & \multicolumn{2}{|l|}{$\begin{array}{l}B \\
n=463\end{array}$} & \multicolumn{2}{|l|}{$\begin{array}{l}C \\
n=465\end{array}$} & \multicolumn{2}{|l|}{$\begin{array}{l}D \\
n=450\end{array}$} & \multicolumn{2}{|l|}{$\begin{array}{l}\text { None } \\
n=623\end{array}$} \\
\hline & Survey & $\begin{array}{l}\text { Survey } \\
2\end{array}$ & Survey & $\begin{array}{l}\text { Survey } \\
2\end{array}$ & $\begin{array}{l}\text { Survey } \\
1\end{array}$ & $\begin{array}{l}\text { Survey } \\
2\end{array}$ & $\begin{array}{l}\text { Survey } \\
1\end{array}$ & $\begin{array}{l}\text { Survey } \\
2\end{array}$ & Survey & $\begin{array}{l}\text { Survey } \\
2\end{array}$ & Survey1 & $\begin{array}{l}\text { Survey } \\
2\end{array}$ \\
\hline & $n=$ & $\mathrm{n}=$ & \multirow{2}{*}{$\begin{array}{l}n= \\
225\end{array}$} & \multirow{2}{*}{$\begin{array}{l}n= \\
220\end{array}$} & \multirow{2}{*}{$\begin{array}{l}n= \\
232\end{array}$} & \multirow{2}{*}{$\begin{array}{l}n= \\
231\end{array}$} & \multirow{2}{*}{$\begin{array}{l}n= \\
239\end{array}$} & \multirow{2}{*}{$\begin{array}{l}n= \\
226\end{array}$} & \multirow{2}{*}{$\begin{array}{l}n= \\
224\end{array}$} & \multirow{2}{*}{$\begin{array}{l}n= \\
226\end{array}$} & \multirow{2}{*}{305} & $n=$ \\
\hline & 1225 & 1221 & & & & & & & & & & 318 \\
\hline Retired & 91 & 132 & 20 & 24 & 19 & 24 & 22 & 19 & 12 & 25 & 18 & 40 \\
\hline (\%) & $(7.8)$ & $(10.9)$ & $(9.6)$ & $(10.9)$ & $(8.6)$ & $(10.4)$ & $(10.0)$ & $(8.6)$ & $(5.7)$ & $(11.2)$ & $(6.0)$ & $(12.6)$ \\
\hline Unemployed & 58 & 57 & 12 & 8 & 12 & 11 & 13 & 11 & 9 & 7 & 12 & 20 \\
\hline (\%) & $(5.0)$ & $(4.7)$ & $(5.8)$ & $(3.6)$ & $(5.4)$ & $(4.8)$ & $(5.9)$ & $(5.0)$ & $(4.25)$ & $(3.1)$ & $(4.0)$ & $(6.2)$ \\
\hline \multicolumn{13}{|l|}{ Health Insurance: } \\
\hline Insured & 1035 & 1152 & 203 & 209 & 209 & 205 & 171 & 210 & 164 & 215 & 288 & 313 \\
\hline (\%) & $(92.6)$ & $(94.7)$ & $(96.2)$ & $(95.4)$ & $(94.6)$ & $(90.3)$ & $(96.1)$ & $(92.9)$ & $(78.8)$ & $(95.1)$ & $(96.0)$ & (98.4) \\
\hline Uninsured & 83 & 64 & 8 & 10 & 12 & 22 & 7 & 16 & 44 & 11 & 12 & 5 \\
\hline (\%) & $(7.4)$ & (5.3) & (3.8) & $(4.6)$ & $(5.4)$ & $(9.7)$ & (3.9) & $(7.1)$ & $(21.2)$ & $(4.9)$ & $(4.0)$ & $(1.6)$ \\
\hline \multicolumn{13}{|l|}{ Homeownership: } \\
\hline Yes & 898 & 1027 & 183 & 171 & 170 & 209 & 164 & 192 & 135 & 175 & 246 & 280 \\
\hline (\%) & $(83.8)$ & $(85.1)$ & $(87.6)$ & $(79.2)$ & $(86.3)$ & $(92.9)$ & $(92.7)$ & $(86.1)$ & $(70.7)$ & $(77.4)$ & $(82.8)$ & $(88.3)$ \\
\hline No & 173 & 180 & 26 & 45 & 27 & 16 & 13 & 31 & 56 & 51 & 51 & 37 \\
\hline (\%) & $(16.2)$ & $(14.9)$ & $(12.4)$ & $(20.8)$ & $(13.7)$ & (7.1) & (7.3) & $(13.9)$ & $(29.3)$ & $(22.6)$ & $(17.2)$ & (11.7) \\
\hline
\end{tabular}


Table 3

The difference in NCDs behavioral risk factors between two surveys

\begin{tabular}{|c|c|c|c|c|}
\hline $\begin{array}{l}\text { NCDs } \\
\text { Risk } \\
\text { Factors }\end{array}$ & Intervention Package a / Group & $\begin{array}{l}\text { First } \\
\text { Survey } \\
(\%)\end{array}$ & $\begin{array}{l}\text { Second } \\
\text { Survey } \\
(\%)\end{array}$ & $\begin{array}{l}\text { Difference (\%) } \\
\text { (95\% Confidence Interval) }\end{array}$ \\
\hline \multirow[t]{5}{*}{ Insufficient Physical Activity } & A & 40 & 25 & $-15(-24,-6)$ \\
\hline & B & 49 & 24 & $-25(-34,-17)$ \\
\hline & $\mathrm{C}$ & 41 & 40 & $-1(-11,8)$ \\
\hline & $\mathrm{D}$ & 53 & 24 & $-29(-38,-20)$ \\
\hline & None & 39 & 40 & $1(-7,8)$ \\
\hline \multirow[t]{5}{*}{ Insufficient Fruit Consumption } & $A$ & 66 & 57 & $-9(-19,0)$ \\
\hline & B & 59 & 53 & $-6(-1,3)$ \\
\hline & C & 68 & 51 & $-17(-27,-8)$ \\
\hline & $\mathrm{D}$ & 72 & 59 & $-13(-22,-4)$ \\
\hline & None & 73 & 56 & $-17(-25,-10)$ \\
\hline \multirow[t]{5}{*}{ Insufficient Vegetable Consumption } & A & 32 & 34 & $2(-6,11)$ \\
\hline & B & 33 & 39 & $6(-2,15)$ \\
\hline & C & 37 & 36 & $-1(-11,9)$ \\
\hline & D & 40 & 47 & $7(-2,16)$ \\
\hline & None & 38 & 37 & $-1(-9,7)$ \\
\hline \multirow[t]{5}{*}{ High Salt Intake } & $A$ & 15 & 13 & $-2(-9,5)$ \\
\hline & B & 19 & 22 & $3(-4,11)$ \\
\hline & C & 5 & 15 & $10(4,16)$ \\
\hline & D & 19 & 22 & $3(-5,11)$ \\
\hline & None & 15 & 13 & $-2(-8,3)$ \\
\hline \multirow{5}{*}{$\begin{array}{l}\text { Current Tobacco } \\
\text { Use }\end{array}$} & $A$ & 16 & 20 & $4(-3,11)$ \\
\hline & B & 20 & 19 & $-1(-8,7)$ \\
\hline & C & 16 & 22 & $6(-2,12)$ \\
\hline & $\mathrm{D}$ & 14 & 14 & $0.3(-6,7)$ \\
\hline & None & 18 & 11 & $-7(-13,1)$ \\
\hline
\end{tabular}

NCDs, Noncommunicable diseases.

a Intervention package A included target-setting. Intervention package B included A plus evidence-based education. Intervention package $\mathrm{C}$ included $\mathrm{B}$ plus operational planning. Intervention package $D$ included plus performance-based financing. 
Table 4

The estimated effects of intervention packages on the NCDs behavioral risk factors

\begin{tabular}{|c|c|c|c|c|c|}
\hline \multirow[t]{2}{*}{ NCDs Risk Factor } & \multirow[t]{2}{*}{ Intervention Package ${ }^{a} /$ Group } & \multicolumn{2}{|l|}{ Unadjusted } & \multicolumn{2}{|c|}{ Adjusted for Socioeconomic Factors } \\
\hline & & Odds Ratio (95\% Cl) & p-value & Odds Ratio (95\% Cl) & p-value \\
\hline \multirow[t]{5}{*}{ Insufficient Physical Activity } & A & $0.49(0.20,1.22)$ & 0.12 & $0.56(0.21,1.51)$ & 0.25 \\
\hline & B & $0.32(0.11,0.88)$ & 0.02 & $0.27(0.09,0.85)$ & 0.02 \\
\hline & C & $0.91(0.25,3.40)$ & 0.89 & $0.81(0.17,3.76)$ & 0.78 \\
\hline & $\mathrm{D}$ & $0.28(0.10,0.75)$ & 0.01 & $0.24(0.08,0.72)$ & 0.01 \\
\hline & None & Reference Group & & & \\
\hline \multirow[t]{5}{*}{ Insufficient Fruit Consumption } & $A$ & $1.44(0.35,5.95)$ & 0.61 & $1.52(0.27,8.62)$ & 0.63 \\
\hline & B & $1.70(0.45,6.35)$ & 0.43 & $1.94(0.38,9.84)$ & 0.42 \\
\hline & $\mathrm{C}$ & $1.04(0.23,4.72)$ & 0.95 & $0.99(0.13,7.32)$ & 0.99 \\
\hline & $\mathrm{D}$ & $1.19(0.35,4.03)$ & 0.78 & $1.42(0.31,6.61)$ & 0.64 \\
\hline & None & Reference Group & & & \\
\hline \multirow[t]{5}{*}{ Insufficient Vegetable Consumption } & $A$ & $1.17(0.37,3.71)$ & 0.79 & $1.13(0.26,4.89)$ & 0.86 \\
\hline & B & $1.39(0.53,3.62)$ & 0.51 & $1.71(0.64,4.54)$ & 0.28 \\
\hline & C & $1.00(0.34,2.91)$ & 0.99 & $0.70(0.19,2.62)$ & 0.59 \\
\hline & $\mathrm{D}$ & $1.39(0.44,4.42)$ & 0.57 & $1.71(0.46,6.43)$ & 0.42 \\
\hline & None & Reference Group & & & \\
\hline \multirow[t]{5}{*}{ High Salt Intake } & A & $1.01(0.33,3.11)$ & 0.98 & $1.04(0.32,3.38)$ & 0.94 \\
\hline & B & $1.45(0.51,4.12)$ & 0.48 & $1.23(0.41,3.70)$ & 0.71 \\
\hline & C & $3.92(1.05,14.63)$ & 0.04 & $4.35(0.80,23.47)$ & 0.08 \\
\hline & $\mathrm{D}$ & $1.43(0.37,5.56)$ & 0.61 & $1.38(0.36,5.33)$ & 0.64 \\
\hline & None & Reference Group & & & \\
\hline \multirow[t]{5}{*}{ Current Tobacco Use } & A & $2.37(1.09,5.18)$ & 0.03 & $1.87(0.83,4.23)$ & 0.13 \\
\hline & B & $1.73(0.65,4.59)$ & 0.27 & $1.47(0.50,4.29)$ & 0.48 \\
\hline & C & $2.54(0.84,7.66)$ & 0.09 & $1.55(0.56,4.29)$ & 0.40 \\
\hline & $\mathrm{D}$ & $1.82(0.81,4.12)$ & 0.15 & $1.24(0.44,3.54)$ & 0.68 \\
\hline & None & Reference Group & & & \\
\hline
\end{tabular}

Note: Boldface indicates statistical significance $(p<0.05)$.

NCDs, Noncommunicable diseases.

a Intervention package A included target-setting. Intervention package B included A plus evidence-based education. Intervention package C included B plus operational planning. Intervention package $D$ included plus performance-based financing.

\section{Discussion}

The effect of four interventional packages on insufficient physical activity, insufficient fruits and vegetable consumption, high salt consumption, and current tobacco use was examined in this trial. NPHWs implemented the interventions at a randomly selected number of CHCs in four Iranian districts. The most basic Intervention Package included target-setting for NPHWs. Evidence-based education, operational planning, and PBF for NPHWs were added to target-setting in other packages. Improvements were observed in only one NCDs risk factor, insufficient physical activity. The most effective Intervention Package included all four interventions. In this study, incentives were paid to enhance the achievement of goals in optimal health behaviors. Previous studies have shown that in areas where access to physicians is difficult, increasing the motivation of NPHWs can pave the way for achieving predetermined goals[34, 35].

Our findings accord with some review studies which shown that interventions in primary health care can significantly improve physical activity compared to other NCDs risk factors, even 6 to 12 months after intervention [36, 37]. A randomized controlled trial (RCT) in the United Kingdom showed 
that motivational interviewing of primary care patients by NPHWs improved physical activity level assessed 12 months after the intervention [38]. Other RCTs also showed interventions with multiple lifestyle improvement components can increase physical activity [39-41].

This study's measured improvements in physical activity can be attributed to the provision of regular physical activity programs by NPHWs to the CHC visitors (2 to 4 times a month), NPHWs' active involvement in physical activity initiatives (e.g., group walking in public areas) and encouraging local councils to waive rent or premium to allocate parks and recreational areas and sports halls to group activities supported by $\mathrm{CHCs}$. The finding that the addition of PBF to other interventions made the results stronger indicates the importance of incentive payments and their role in promoting NPHW' efforts. A similar study in San Diego, California, USA, included direct involvement of health workers in public exercises and group walking over 12 months measured a noticeable increase in physical activity in the community $[42,43]$. Other studies have also shown the effectiveness of communitybased physical activity interventions [44, 45].

An irregularity was found in the results for physical activity. It was expected that adding more components to the Intervention Package make it more effective. Accordingly, the addition of evidence-based training to goal-setting made the effect larger and statistically significant. However, the addition of an action plan to the Intervention Package without PBF eradicated the effect of goal-setting and evidence-based training. Adding PBF to the package, on the other hand, significantly increased the magnitude of the effect. Therefore, an action plan without incentive payment appeared to be an ineffective intervention. This irregularity may be an important result of this study. Anecdotal evidence collected by the authors showed that some NPHWs of CHCs who received Intervention Package with and without incentive payments (packages $\mathrm{C}$ and D) might be communicating during the study period. Hence, no incentive payment to NPHWs who implemented the Intervention Package C might have acted as a disincentive. At the same time, they were expected to do the same amount of work as NPHWs who implemented the Intervention Package D.

Another potentially important result was the unexpectedly slight improvement of adding PBF to evidence-based training in decreasing the odds of insufficient physical activity, as the adjusted odds ratios of Intervention Packages B and D were 0.27 (95\% Cl: 0.09, 0.85) and 0.24 (95\% Cl: 0.08, 0.72), respectively. Although there are wide uncertainties for both estimates, it seemed PBF only marginally improved the effectiveness of the interventions. This finding highlights the critical role of providing evidence-based training to the participating NPHWs.

The goal of increasing fruits and vegetable consumption may be achievable by spending more time and holding counselling sessions, as other studies have shown $[46,47]$. On the other hand, failure to achieve this goal might be due to the high inflation rate in the country during the study period, especially the sharp increase in food, fruit, and vegetable prices because of a new round of international economic sanctions on the country from 2018 [48]. Virtually, the average cost of food in 2019 was estimated to be 3.6 times more than that in 2017 [49]. Factors influencing failure to achieve the desired effect of interventions in the consumption of fruits and vegetables have been reported before. Poor nutritional knowledge [50], the role of media in advertising food with low nutritional value [51], the high relative price of fruits [52] are posed as the main factors.

Measuring no improvement in reducing high salt intake in this study is consistent with the contemporary consumption habits in the country and the challenges of changing them. Despite the health risks associated with high salt intake and the realization that a $30 \%$ reduction in salt intake can reduce cardiovascular disease mortality by about $17 \%$ by 2030 , salt consumption in Iran is twice the recommended consumption by the WHO [53]. Evidence has shown that changing behavior and modifying consumption patterns require comprehensive and extensive programs [54]. Other studies have shown that changing the habit of salt consumption is less probable only with educational and information campaigns [55, 56]. One potential challenge in reducing salt intake in rural Iran may be the presence of traditional healers who disseminate rumours mixed with religious stories about the benefits of using salt, salt stone, and sea salt, even for people with hypertension [57].

No measured effect of this study's interventions on tobacco use was expected as influencing tobacco use habits faces easy access and low price challenges. An extensive literature on the economics of smoking shows that policies that increase the price of tobacco products (though increased sales taxes, for example) are most influential in decreasing tobacco use [58-62]. Such macro-level policies were out of this study's scope.

This study has several limitations. First, only short-term effects were measured because individuals in the intervention CHCs were not followed up. The trial was initially designed for 24 months [17]. Nonetheless, in compliance with limitations imposed by the emergence of the COVID-19 pandemic and the required social distancing policies, the study was stopped prematurely. Similar studies with longer periods of interventions might be necessary to measure longer-term effects on NCDs Behavioral risk factors. Second, the survey participants were not necessarily the ones who were directly affected by the interventions. Therefore, the measured effects may reflect the lower bounds of the actual effects. Third, participating NPHWs' relocation to serve in other CHCs was out of the researchers' control. However, all relocations were traced, and replacing NPHWs received the same training. Fourth, simultaneous national research projects, such as the High Blood Pressure Campaign, were not under the researchers' control [63]. However, it is expected that such factors affected all intervention and non-intervention groups similarly.

\section{Conclusion}

Paying incentives to NPHWs along with other interventions could be considered a useful means of improving physical activity in the community. This study could not be continued because of COVID-19. Longer studies are needed to identify the long-term effects of such interventions.

\section{Abbreviations}


NCDs

Noncommunicable diseases

UN

United Nations

LMICs

Low- and Middle-Income Countries

SDGs

Sustainable Development Goals

WHO

World Health Organization

IraPEN

Iranian Package of Essential Noncommunicable diseases

NPHWs

Non-Physician community Health Workers

CHCs

Community Health Centers

STEPS

Stepwise approach to Surveillance

COVID-19

Coronavirus Disease of 2019

PBF

Performance-Based Financing

MOHME

Ministry of Health \& Medical Education

MET

Metabolic Equivalent of Task

DID

Difference-In-Difference

RCT

Randomized Controlled Trial.

\section{Declarations}

\section{Ethics approval and consent to participate}

This study has been approved by the national committee on ethics in medical research (code: IR.NIMAD.REC.1396.084) as well as our institutional review board (code: IR.IUMS.REC.1395.1057613). Written informed consent will be obtained from study participants.

\section{Consent for publication}

Not applicable.

\section{Availability of data and materials}

The datasets generated and/or analyzed during the current study are not publicly available as publications are planned but are available from the corresponding author on reasonable request.

\section{Competing interests}

The authors declare that they have no competing interests.

\section{Funding}

Research reported in this publication was supported by Elite Researcher Grant Committee under award number 958058 from the National Institutes for Medical Research Development (NIMAD), Tehran, Iran. 


\section{Authors' contributions}

The study was designed by MML, MN, ATB, MAA, and SMK. MML, ATB, FMH, EB, and MAA were involved in the implementation and execution phase. Statistical Analysis was performed by MML, MAA, SMK and LJ. The whole project was supervised by MML, ATB and FMH. All authors were involved in drafting or critical review of the manuscript. All authors read and approved the submitted version.

\section{Acknowledgements}

Research reported in this publication was supported by Elite Researcher Grant Committee under award number 958058 from the National Institutes for Medical Research Development (NIMAD), Tehran, Iran. The authors would like to thank the vice-chancellors of Public Health at Iran University of Medical Sciences (Tehran, Iran), Semnan University of Medical Sciences (Semnan, Iran), and Bushehr University of Medical Sciences (Bushehr, Iran) and the involved healthcare workers of Shahriar, Damghan, Garmsar and Borazjan for their contribution to this project. A full list of the collaborators of this study is available in the electronic Additional file 3

\section{References}

1. GBD. Global Burden of Disease Study 2019: Institute for Health Metrics and Evaluation (IHME). 2020 [Available from: http://ghdx.healthdata.org/gbd-results-tool.

2. WHO. Guidance note on the integration of noncommunicable diseases into the united nations development assistance framework World Health Organisation; 2019 [Available from: https://www.who.int/nmh/ncd-task-force/guidance-note.pdf.

3. WHO. World health statistics 2016: monitoring health for the SDGs sustainable development goals: World Health Organization; 2016 [Available from: https://apps.who.int/iris/handle/10665/206498.

4. GBD. Global Burden of Disease Study 2019: nstitute for Health Metrics and Evaluation (IHME); 2019 [Available from: https://vizhub.healthdata.org/gbd-compare/.

5. GBD. Global burden of diseases 2017: Institute for Health Metrics and Evaluation, University of Washington; 2019 [Available from: https://vizhub.healthdata.org/gbd-compare/.

6. Kyu HH, Abate D, Abate KH, Abay SM, Abbafati C, Abbasi N, et al. Global, regional, and national disability-adjusted life-years (DALYs) for 359 diseases and injuries and healthy life expectancy (HALE) for 195 countries and territories, 1990-2017: a systematic analysis for the Global Burden of Disease Study 2017. The Lancet. 2018;392(10159):1859-922.

7. Khorrami Z, Etemad K, Yarahmadi S, Khodakarim S, Kameli M, Hezaveh AM, et al. Urbanization and noncommunicable disease (NCD) risk factors: WHO STEPwise Iranian NCD risk factors surveillance in 2011. East Mediterr Health J. 2017;23(7):469.

8. WHO. Global status report on noncommunicable diseases 2010 Geneva: World Health Organization Regional Office for the Western; 2011 [Available from: https://www.who.int/nmh/publications/ncd_report_full_en.pdf.

9. WHO. WHO STEPS Surveillance Manual: STEPwise Approach to Non Communicable Disease risk factors surveillance Geneva: World Health Organization; 2017 [Available from: http://www.who.int/ncds/surveillance/steps/en/.

10. WHO. Non communicable diseases in World Health Organization Geneva2018 [Available from: http://www.who.int/mediacentre/factsheets/fs355/en/.

11. WHO. Increasing fruit and vegetable consumption to reduce the risk of noncommunicable diseases: World Health Organization; 2019 [Available from: https://www.who.int/elena/titles/fruit_vegetables_ncds/en/.

12. WHO. Management of noncommunicable diseases: World Health Organization; 2019 [Available from: https://www.who.int/activities/management-of-noncommunicable-diseases.

13. WHO. A prioritized research agenda for prevention and control of noncommunicable diseases in 2011: World Health Organization; 2011 [Available from: https://apps.who.int/iris/handle/10665/44569.

14. WHO. Islamic Republic of Iran on a fast-track to beating noncommunicable diseases 2017 [Available from: https://www.who.int/newsroom/feature-stories/detail/islamic-republic-of-iran-on-a-fast-track-to-beating-noncommunicable-diseases.

15. Davari M, Haycox A, Walley T. Health care challenges in Iran. Iran J Public Health. 2005;34(Supple 1):30-1.

16. Etemad K, Heidari A, Panahi M, Lotfi M, Fallah F, Sadeghi S. A Challenges in Implementing Package of Essential Noncommunicable Diseases Interventions in Iran's Healthcare System. J Health Res Commun. 2016;2(3):32-43.

17. Asadi-Aliabadi M, Tehrani-Banihashemi A, Mirbaha-Hashemi F, Janani L, Babaee E, Karimi SM, et al. Evaluating the impact of results-based motivating system on noncommunicable diseases risk factors in Iran: Study protocol for a field trial. Med J Islam Repub Iran. 2021;35:66.

18. Djalalinia S, Modirian M, Sheidaei A, Yoosefi M, Zokaiee H, Damirchilu B, et al. Protocol design for large-scale cross-sectional studies of surveillance of risk factors of non-communicable diseases in Iran: STEPs 2016. Arch Iran Med. 2017;20(9):--

19. SCI. Population and Housing Censuses: Statistical Center of Iran; 2016 [Available from: https://www.amar.org.ir/english/Population-and-HousingCensuses.

Page $13 / 16$ 
20. Parliament. The fifth development plan act: The Parliament of Iran; 2010 [Available from: http://rc.majlis.ir/fa/law/print_version/790196.

21. Campbell MK, Piaggio G, Elbourne DR, Altman DG. Consort 2010 statement: extension to cluster randomised trials. Bmj. $2012 ; 345$.

22. Gelband H, Jha P, Sankaranarayanan R, Gauvreau C, Horton S. Cancer: Disease Control Priorities. 3. third ed. Washington, DC: The International Bank for Reconstruction and Development / The World Bank (C) 2015 International Bank for Reconstruction and Development / The World Bank.; 2015.

23. Prabhakaran D, Anand S, Watkins D, Gaziano T, Wu Y. al. e. Cardiovascular, Respiratory, and Related Disorders: Key Messages on Essential Interventions to Address its Burden in Low-and Middle-Income Countries Disease Control Priorities. 5. third ed. Washington, DC: The International Bank for Reconstruction and Development / The World Bank @ 2017 International Bank for Reconstruction and Development / The World Bank.; 2015.

24. WHO. WHO package of essential noncommunicable (PEN) disease interventions for primary health care 2020 [Available from: https://www.who.int/publications/i/item/who-package-of-essential-noncommunicable-(pen)-disease-interventions-for-primary-health-care.

25. MOHME. National action plan for non-communicable diseases prevention and control in Iran 2015-2025: Iranian National Committee for NCDs Prevention and Control; 2015 [Available from: https://iums.ac.ir/files/vch/files/sanad_meli.pdf.

26. CBI. Monthly economic indicators and statistics: Central bank of Islamic Republic of Iran; 2019 [Available from: https://www.cbi.ir/page/19712.aspx.

27. Ainsworth BE, Haskell WL, Whitt MC, Irwin ML, Swartz AM, Strath SJ, et al. Compendium of physical activities: an update of activity codes and MET intensities. Med Sci Sports Exerc. 2000;32(9):SUPP/1):S498-504.

28. Agudo A, Joint FAOWHOWoF. Vegetables for H. Measuring intake of fruit and vegetables [electronic resource] / Antonio Agudo. World Health Organization; 2005.

29. MOHME. A set of basic interventions for non-communicable diseases in the primary health care system of Iran (IraPEN for physician) 2016 [Available from: https://iums.ac.ir/files/vch/files/dastorolamal-pezeshk(1).pdf.

30. WHO. Food-based dietary guidelines in the WHO European Region World Health Organization. Copenhagen: WHO Regional Office for Europe; 2003 [Available from: https://www.euro.who.int/en/health-topics/disease-prevention/nutrition/publications/technical-documents/dietaryrecommendations-and-nutritional-requirements/food-based-dietary-guidelines-in-the-who-european-region.

31. WHO. WHO STEPS, Noncommunicable Disease Risk Factor. Survey 2016 [Available from: https://cdn.who.int/media/docs/defaultsource/ncds/ncd-surveillance/steps/part6-section-3c-databook-template-v3-2.pdf?sfvrsn=99cfe694_2.

32. WHO. Prevalence of current (daily or occasional) tobacco smoking among adults (15 years and older) (percentage) [Available from: https://www.who.int/whosis/whostat2006TobaccoAdults.pdf.

33. Bertrand M, Duflo E, Mullainathan S. How much should we trust differences-in-differences estimates? Q J Econ. 2004;119(1):249-75.

34. Jung DH, Palta M, Smith M, Oliver TR, DuGoff EH. Differences in Receipt of Three Preventive Health Care Services by Race/Ethnicity in Medicare Advantage Plans: Tracking the Impact of Pay for Performance, 2010 and 2013. Prev Chronic Dis. 2016;13:E125-E.

35. Doran T, Fullwood C, Kontopantelis E, Reeves D. Effect of financial incentives on inequalities in the delivery of primary clinical care in England: analysis of clinical activity indicators for the quality and outcomes framework. The Lancet. 2008;372(9640):728-36.

36. Hayes L, McParlin C, Azevedo LB, Jones D, Newham J, Olajide J, et al. The Effectiveness of Smoking Cessation, Alcohol Reduction, Diet and Physical Activity Interventions in Improving Maternal and Infant Health Outcomes: A Systematic Review of Meta-Analyses. Nutrients. 2021;13(3):1036.

37. Murray JM, Brennan SF, French DP, Patterson CC, Kee F, Hunter RF. Effectiveness of physical activity interventions in achieving behaviour change maintenance in young and middle aged adults: a systematic review and meta-analysis. Soc Sci Med. 2017;192:125-33.

38. Hardcastle SJ, Taylor AH, Bailey MP, Harley RA, Hagger MS. Effectiveness of a motivational interviewing intervention on weight loss, physical activity and cardiovascular disease risk factors: a randomised controlled trial with a 12-month post-intervention follow-up. Int J Behav Nutr Phys Act. 2013;10(1):1-16.

39. Pulling Kuhn A, Stoepker P, Dauenhauer B, Carson RL. A systematic review of multi-component comprehensive school physical activity program (CSPAP) interventions. Am J Health Promot. 2021:08901171211013281.

40. Rezola-Pardo C, Rodriguez-Larrad A, Gomez-Diaz J, Lozano-Real G, Mugica-Errazquin I, Patiño MJ, et al. Comparison Between Multicomponent Exercise and Walking Interventions in Long-Term Nursing Homes: A Randomized Controlled Trial. Gerontologist. 2020;60(7):1364-73.

41. Simons-Morton DG, Calfas KJ, Oldenburg B, Burton NW. Effects of interventions in health care settings on physical activity or cardiorespiratory fitness. Am J Prev Med. 1998;15(4):413-30.

42. Kassavou A, Turner A, French DP. Do interventions to promote walking in groups increase physical activity? A meta-analysis. Int J Behav Nutr Phys Act. 2013;10(1):1-12.

43. Lai AY, Lam EY, Fabrizo C, Lee DP, Wan AN, Tsang JS, et al. A community-based lifestyle-integrated physical activity intervention to enhance physical activity, positive family communication, and perceived health in deprived families: a cluster randomized controlled trial. Public Health Front. 2020;8:434.

44. Bopp M, Fallon E. Community-based interventions to promote increased physical activity. Appl Health Econ Health Policy. 2008;6(4):173-87. 
45. Israel BA, Schulz AJ, Parker EA, Becker AB. Review of community-based research: assessing partnership approaches to improve public health. Annu Rev Public Health. 1998;19(1):173-202.

46. Krist AH, Davidson KW, Mangione CM, Barry MJ, Cabana M, Caughey AB, et al. Behavioral counseling interventions to promote a healthy diet and physical activity for cardiovascular disease prevention in adults with cardiovascular risk factors: US Preventive Services Task Force recommendation statement. JAMA. 2020;324(20):2069-75.

47. Resnicow K, Jackson A, Wang T, De AK, McCarty F, Dudley WN, et al. A motivational interviewing intervention to increase fruit and vegetable intake through Black churches: results of the Eat for Life trial. Am J Public Health. 2001;91(10):1686-93.

48. Khatibi SR, Karimi SM, Moradi-Lakeh M, Kermani M, Motevalian SA. Fossil energy price and outdoor air pollution: predictions from a QUAIDS model. Biofuel Res J. 2020;7(3):1205-16.

49. Hejazi J, Emamgholipour S. The effects of the re-imposition of US sanctions on food security in Iran. Int J Health Policy Manag. 2020.

50. Salehi L, Eftekhar H, Mohammad K, Tavafian SS, Jazayery A, Montazeri A. Consumption of fruit and vegetables among elderly people: a cross sectional study from Iran. Nutr J. 2010;9(1):1-9.

51. Pomerleau J, World Health O, Joint FAOWHOWoF. Vegetables for $\mathrm{H}$. Effectiveness of interventions and programmes promoting fruit and vegetable intake [electronic resource]. World Health Organization; 2005.

52. Van Duyn MAS, Kristal AR, Dodd K, Campbell MK, Subar AF, Stables G, et al. Association of awareness, intrapersonal and interpersonal factors, and stage of dietary change with fruit and vegetable consumption: a national survey. Am J Health Promot. 2001;16(2):69-78.

53. Rezaei S, Mahmoudi Z, Sheidaei A, Aryan Z, Mahmoudi N, Gohari K, et al. Salt intake among Iranian population: the first national report on salt intake in Iran. J Hypertens. 2018;36(12):2380-9.

54. Trieu K, McMahon E, Santos JA, Bauman A, Jolly K-A, Bolam B, et al. Review of behaviour change interventions to reduce population salt intake. Int J Behav Nutr Phys Act. 2017;14(1):1-15.

55. Cotter J, Cotter MJ, Oliveira P, Cunha P, Polónia J. Salt intake in children 10-12 years old and its modification by active working practices in a school garden. J Hypertens. 2013;31(10):1966-71.

56. Veroff DR, Sullivan LA, Shoptaw E, Venator B, Ochoa-Arvelo T, Baxter JR, et al. Improving self-care for heart failure for seniors: the impact of video and written education and decision aids. Popul Health Manag. 2012;15(1):37-45

57. Mokhtari M, Vahid H. Salt and its Role in Health and Disease Prevention from the Perspectives of Iranian Medicine and Modern Medicine. Iran J Med Sci. 2016;41(3 Suppl):58.

58. Doubeni CA, Li W, Fouayzi H, DiFranza JR. Perceived accessibility of cigarettes among youth: a prospective cohort study. Am J Prev Med. 2009;36(3):239-42.

59. Homaie Rad E, Pulok MH, Rezaei S, Reihanian A. Quality and quantity of price elasticity of cigarette in Iran. Int J Health Plann Manage. 2021;36(1):60-70.

60. Mayne SL, Gordon-Larsen P, Schreiner PJ, Widome R, Jacobs DR, Kershaw KN. Longitudinal associations of cigarette prices with smoking cessation: the coronary artery risk development in young adults study. Nicotine Tob Res. 2019;21(5):678-85.

61. Mistry R, Pednekar MS, Gupta PC, Raghunathan TE, Appikatla S, Puntambekar N, et al. Longitudinal study of adolescent tobacco use and tobacco control policies in India. BMC Public Health. 2018;18(1):1-8.

62. Poorolajal J, Mohammadi Y, Mahmoodi A. Challenges of tobacco control program in Iran. Arch Iran Med. 2017;20(4):0-

63. Maftoon F, Aghasi M, Rafiee Bahabadi M. A national campaign on 'High Blood Pressure Control'in Iran: A rapid evaluation. Payesh Health Monit. 2020:0-.

\section{Figures}




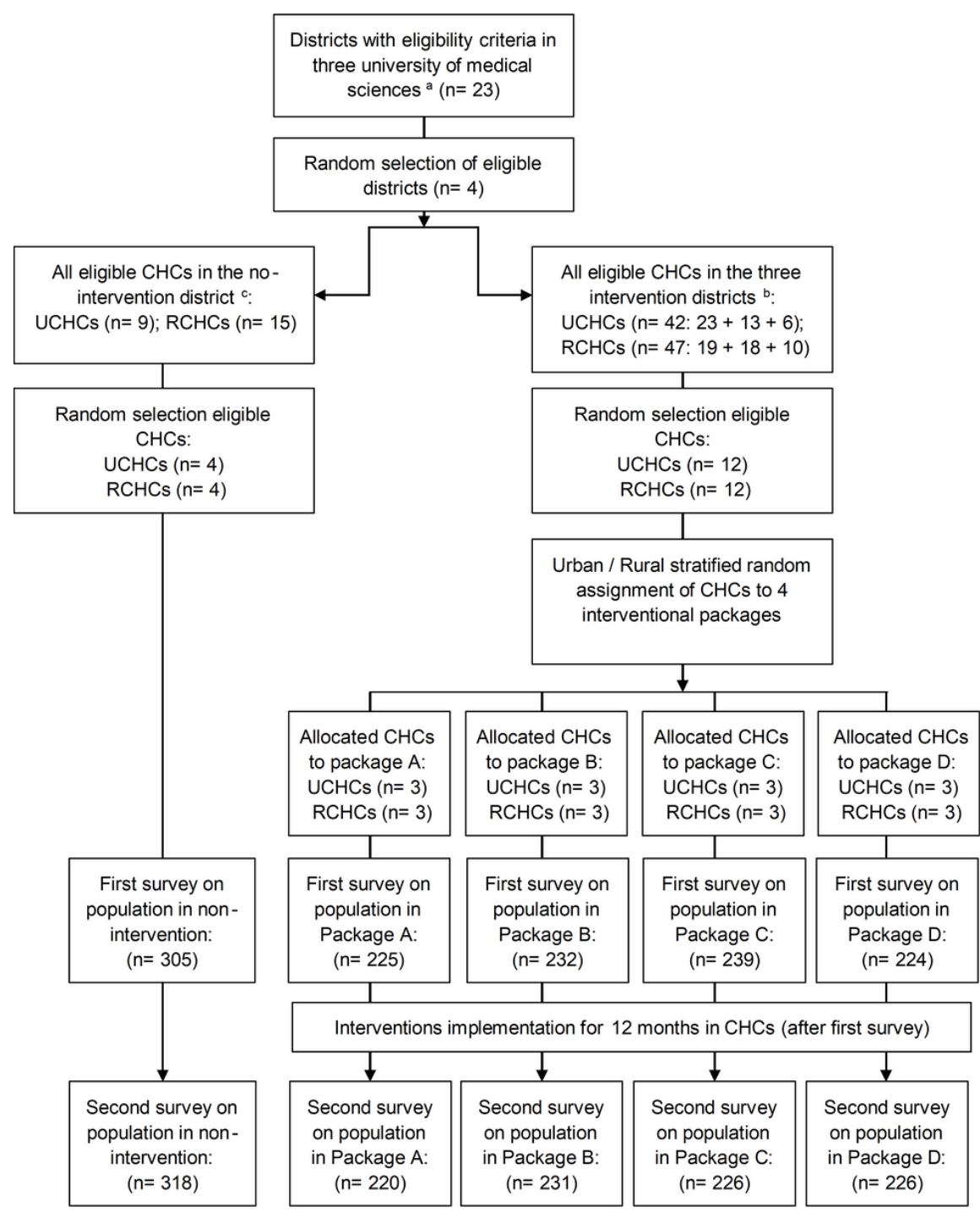

Figure 1

CONSORT flow diagram

Note: Analysed based on population in first and second surveys.

a These three universities are located in three provinces of Tehran, Semnan, and Bushehr in Iran, and one of the main tasks of them are to provide primary health services to the covered population.

b Shahriar, Dashtestan, and Damghan.

${ }^{\mathrm{c}}$ Garmsar.

\section{Supplementary Files}

This is a list of supplementary files associated with this preprint. Click to download.

- Additionalfile1.docx

- Additionalfile2CONSORTchecklist.docx

- Additionalfile3.docx 